\title{
Collaborative Learning in a Multilingual Class
}

\author{
Deonarain Brijlall \\ School of Science, Mathematics and Technology Education, University of KwaZulu-Natal \\ brijlalld@ukzn.ac.za
}

The solving of word problems dealing with fractions was investigated. Two sets of learners worked in solving the same tasks on fractions. One set of learners worked collaboratively and the other group consisted of learners working independently. The selected participants consisted of two Grade 8 classes at a high school in Pietermaritzburg, South Africa. The study was a qualitative one involving lesson observations, analysis of learner worksheets, questionnaires and interviews. The two tasks were presented in the form of word problems and the classroom comprised of multilingual learners. Data yielded by these research instruments confirmed assumptions and literature claims. Although it was a small scale qualitative research, interesting observations were made that could have pedagogical implications.

In South Africa learners have difficulty grasping key mathematical concepts. This was illustrated in the TIMMS 2003 report, where it was suggested that ninety percent of South African learners do not possess a basic mathematical knowledge as opposed to the international average of less than thirty percent. Only 0,3 percent of Grade 8 learners in South Africa could be classified as being able to solve non-routine problems (Reddy, 2006). A major concern in South Africa is that learners will not be competent enough in mathematics to advance to tertiary institutions and pursue careers in the science and technology fields. To ensure a better economy in South Africa, a dramatic improvement must occur in the teaching of mathematics and more specifically, in the development of problem solving skills at school level. Learners are not given enough problem solving opportunities at school to improve their problem solving abilities.

The lack of problem solving skills in South Africa may perhaps be a result of the way it has been taught in schools. In the past, problem solving tasks were solved individually by learners. Problems presented to learners are usually abstract and foreign to them, therefore they generally acquire a dislike to problem solving tasks, believing they will be too difficult to solve. This is especially true for learners who are not achievers at mathematics (Barns, 2005) or low attainers, as they are referred to in this paper. We decided therefore to gauge whether learners would achieve success in a group environment. In this regard we raised the following question:

Does collaborative learning in a multilingual classroom yield greater success in problem solving as compared to individual engagement?

\section{Relevance of study to the South African context}

In the past ten years, not many papers reporting on learning in a multilingual classroom have been published locally (Setati \& Barwell, 2008). We therefore decided to investigate the learning of mathematics by learners versed in different languages. In order to encourage mathematical problem solving, we allowed learners to discuss the understanding and solution of the word problems (presented in English) in the language the learner was comfortable with. It was found by Dlamini (2008) that second language English learners obtained exceptional results in mathematics but performed poorly in English. We therefore in our investigation motivated us to let learners engage the solution of the problems in their indigenous languages.

Since the teacher is seen as a source of knowledge, learners constantly seek their advice and avoid tackling the problem amongst group members. For 
true problem solving skills to develop, learners need to work independently as well as interdependently with class mates. Problem solving and working together in groups are part of the critical outcomes in the Revised National Curriculum Statement (RNCS) for Mathematics Grades 1-9 (Department of Education, 2002). Problem solving is continually mentioned in the learning outcomes. However, problem solving skills are considered poor in South Africa (Buffer \& Leigh, 2005; Arora, 2003). If the approach to problem solving was modified and made less daunting to learners, a change in their attitude towards mathematics in general and more specifically towards problem solving may be achieved.

\section{Multilingualism}

The diverse nature of multilingualism around the world is reflected in the wide range of multilingual classrooms in which mathematics is taught (Barwell, 2005).We see a classroom as being multilingual if any of the participants (learners, teachers or others) is potentially able to draw on more than one language as they go through their work. This paper adopts this definition when it refers to a multilingual environment (when referring to the classroom in which learners with different mother tongue languages engaged in the problem solving activities). The learners draw from English, Afrikaans, isiZulu, Sisuthu, Sotho and Swati.

\section{Realistic mathematics education}

Realistic Mathematics Education (RME) is a theory designed by the Hungarian Hans Freudenthal (Barns, 2005). He considered mathematics to be a human activity and thus believed that to learn mathematics one had to do mathematics. It focuses, as Barns (2005) points out, the need to use learner's everyday experiences in order for them to unfold mathematics by themselves and that mathematics is rather not a 'ready-made system with general applicability' (p. 50). With this in mind RME lines up with the RNCS as the RNCS calls for teaching to become more learner centred. The RNCS also stresses the importance of interaction with others. RME allows for such interaction as real world problems are normally solved in a group environment, where all participants work together to solve the problem at hand, rather than solving it individually. This paper focuses on the rational number system. Kilpatrick, Swafford and Findell (2001) note that in the USA many learners find the rational number system difficult.

\section{Problem solving}

Questions used in problem solving tasks must be familiar to the learner. The context of the question must be a reflection of the learners' socioeconomic background in order to make it "realistic" to their personal experience. As Cooper and Dunne (2004) suggest, working-class learners do not experience the same background as middleclass learners, hence will not find the same questions "realistic". By realistic it is meant that the mathematical task has been designed within a context the learner is familiar with. This is also true regarding learner's gender, home language and cultural grouping. As a result learners' mathematical abilities may well be underestimated when related to the context in which the question is asked. For this reason two problem tasks used in the study were related to the learners' personal knowledge and background. Learners were allowed to query the meanings of words used in the problem statement. They were also allowed to discuss these meanings in their home language when sitting with colleagues who had a similar home language.

The rational number system is represented in a number of ways. The study focused on common fractions and decimal fractions. Kilpatrick et al. (2001) believe that the informal knowledge learners possess in "sharing and measuring" is the foundation that rational numbers can be built upon. They also note that children struggle to link different forms of rational numbers as they battle to see how they are related. They suggest that for effective teaching to take place it would depend on how cognitively demanding the given tasks were. Mathematics should be elaborated through tasks and sufficient time must be allocated to master each task. Learners must also be given the opportunity to link their informal knowledge with the abstract knowledge of mathematics. Kilpatrick et al. (2001) distinguish five strands of mathematical proficiency, namely: conceptual understanding, procedural fluency, strategic competence, adaptive reasoning and productive disposition. Different strategies have been suggested to attempt improving mathematics, one such strategy is collaborative learning

\section{Methodology}

A qualitative research approach was employed in this research. This was achieved through the collection of data via observation of a lesson, analysis of learners' worksheets, questionnaires 
and interviews of participants. The selected participants consisted of two Grade 8 mathematics classes at a high school in Pietermaritzburg, South Africa. This school is a co-educational, with multilingual classrooms and mixed socio-economic backgrounds. The participants have a mixed ability in mathematics. Learners were divided into two groups, the control group and the experimental group. The learners in the two classes were ranked in descending order of their average mathematics marks for the first two terms. Every second learner was placed in the experimental group while the remaining learners were placed in the control group. This was to ensure learners with the same academic levels were present in both the control group and experimental group. The control group was given the activity to complete individually. This group completed the activity at the same time as the experimental group and was therefore supervised by a different teacher to that of the experimental group. The experimental group was further divided into seven groups of four and the control group comprised twenty three. Learners were arranged in groups ensuring that the members in each group had an array of mathematical abilities (based on their previous performance). The researcher observed the experimental group.

Problem solving worksheets were used to gather information. The worksheets formed the foundation of the qualitative study and comprised of two tasks: one involved decimal fractions, the other common fractions. Both tasks demanded problem solving skills and both experimental and control groups confronted these problems. In the experimental group learners were asked to initially complete the worksheet on their own and then they were placed in groups where a discussion was held amongst the group members. This was to promote participation by learners when working in a group. At the end of the discussion, each group was asked to complete a worksheet that expressed the joint views of the group. A fifty minute lesson was provided for learners to solve the problem.

Eight learners were selected to be interviewed. We found it difficult to interview all group members and interviewed four representatives form different groups and four from the control lot. The representatives from the groups were chosen by the members of the particular groups. The learners belonging to the control group worked individually. These learners had been linked to each spokeswoman from the experimental group. The linkage was done by choosing the control group interviewees with similar mathematical performance as their counterparts from the experimental groups. The interview was conducted in an informal manner to clarify answers given by learners in the worksheet. The interview focused on the learners' understanding of the questions and their personal experience of either working individually or as part of a group. Learners were also asked to comment on how the lesson may have been improved.

\section{Diversity of learners}

Fifty one learners completed the questionnaires. The diversity of learners is discussed under the headings of age, gender, home language, mother tongue language, medium of instruction and racial group. We have regarded home language as the most used language when communicating at home. This to us might be different from the mother tongue language which we adopt to refer to language associated to the individual via past generations. For example, the Indian child in class was Hindi speaking (as mother tongue), but English speaking (as home language).

\section{Age}

Table 1: Age of learners

\begin{tabular}{|l|c|c|c|c|c|c|}
\hline Age & 13 & 14 & 15 & 16 & Unknown & Total \\
\hline Number & 10 & 34 & 5 & 1 & 1 & 51 \\
\hline
\end{tabular}

Table 1 shows that the age of the learners ranged from thirteen years to sixteen years old. Two thirds of the learners were fourteen years old. Thirteen and fourteen year old learners comprised 86 percent of the participants.

\section{Gender}

Sixty nine percent of learners were male and thirty one percent females.

\section{Home language}

Learners were asked to indicate their home language. Home language is the preferred language in which the learners communicate at home. As indicated in Table 2, isiZulu is the dominant language with 58 percent of learners communicating in isiZulu. One learner indicated Afrikaans as home language. English was spoken

Table 2: Home language of learners

\begin{tabular}{|c|c|c|c|c|c|}
\hline Afrikaans & English & isiZulu & Other & More than 1 & Total \\
\hline 1 & 17 & 30 & 6 & 3 & $54-3=51$ \\
\hline
\end{tabular}


Table 3: Mother tongue language of learners

\begin{tabular}{|c|c|c|c|c|c|c|}
\hline Afrikaans & English & isiZulu & Other & More than 1 & No answer & Total \\
\hline 2 & 14 & 28 & 7 & 1 & 1 & $52-1=51$ \\
\hline
\end{tabular}

by only 33 percent of learners. Six learners indicated they spoke a language which was not listed in the questionnaire. These languages were Xhosa (four), Sisuthu (one), Sotho (one) and Swati (one). Three learners indicated more than one home language. This demonstrates the diversity of home languages spoken by the learners with the most speaking isiZulu.

\section{Mother tongue language}

Under the category mother tongue, learners were asked to indicate the language that they most identify with. The majority of learners identified with isiZulu although the number decreased slightly compared to home language. English also decreased from 33 percent to 27 percent. One learner did not indicate an answer and one learner indicated two languages. Seven learners selected the category "other". The languages not indicated on the questionnaire and that were mentioned by learners were: Xhosa (four), Sisuthu (one), Sothu (one) and Swati (one).

\section{Language of education}

All learners indicated that they are educated in English (meaning being taught in the medium of English). Four learners indicated that they had been educated in two languages. The languages they indicated referred to their first additional language. What should be noted is that all learners were taught in English while only twenty-seven percent of learners indicated their mother tongue language as English and only thirty-three percent of learners indicated English as their home language. This means that the majority of learners taking part in the study were second language English speakers. It must be emphasised that despite presenting the problems in English, the participants in the group were allowed to communicate in their home language.

\section{Racial group}

Table 4: The racial grouping of learners

\begin{tabular}{|c|c|c|c|c|c|}
\hline Black & White & Coloured & Indian & Other & Total \\
\hline 34 & 8 & 7 & 1 & 1 & 51 \\
\hline
\end{tabular}

Table 4 depicts that a variety of racial groups were represented by the learners who participated in the research. One learner selected other and indicated he was Muslim. Two thirds of learners were black, while the other third comprised of white, coloured, Indian and Muslim learners.
The questionnaire showed that all participants received their education in English. This is in contrast to most learners' mother tongue and home language as the questionnaire reveals that most learners' home and mother tongue language is isiZulu. Most participants were black males. The questionnaire does however show a diverse multicultural sample group.

\section{Collaborative learning versus individual attempt}

For analysis purposes only those seven learners from the control group who were linked to the seven group representatives from the experimental group were used in the comparison. To obtain anonymity and distinguish between learners, the following codes were used. When referring to the group leaders, a "G" is used as opposed to individual learners where an "I" was used. A number was also shown to illustrate the group in which the learners were from or the corresponding individual learner. For example group leader 3 was coded as G3 and individual learner who was linked to group 2 was denoted as I2. G2.2 belonged to group 2 but was not the leader. The data collected from individual learners and the groups of learners was compared and analysed under the following sub-headings namely, results from problem task 1 , and results from problem task 2 .

\section{Results from problem 1}

The first problem task given to learners was:

A large piece of cardboard paper is $0,01 \mathrm{~mm}$ thick. It is cut in half and one piece is placed on the other to make a pile. These are cut in half and all four pieces are placed in a pile. These four are cut in half and placed in a pile, and the process is continued. After the pieces have been cut and piled for the tenth time, what is the height of the pile in centimetre?

The data collected from question one was separated into categories to make it easier to compare. The categories used were: (A) mathematically sound calculation with an accurate answer, (B) accurate answer with no calculation shown, (C) correct solution with incorrect conversion, (D) partially correct solution with calculation shown, (E) no understanding of the question, (F) Incorrect answer with no calculation shown and (G) no answer shown. Learners who obtained the correct answer and displayed a 
mathematically sound argument including a correct conversion fell into category "A". Category "B" was selected if a learner achieved the right answer but failed to show a method as it is unclear if the learner had a mathematically sound methodology. If a learner was able to achieve a mathematically sound answer before the conversion, and proceeded to either not convert or convert incorrectly, they were placed in group "C". A learner who had an incorrect answer but had initially shown correct methodology was placed in Category "D". Learners were placed in group "E" if their method of solving the problem had no link to the question and hence showed the learner did not have a clear understanding of the question. If only an incorrect answer was shown, they were placed in category " $F$ ". If the question was left blank, it was placed in category "G".

Table 5: Categorising learners' results for problem 1

\begin{tabular}{|l|c|c|c|c|c|c|c|}
\hline & A & B & C & D & E & F & G \\
\hline Group & 2 & 0 & 5 & 0 & 0 & 0 & 0 \\
\hline Individual & 0 & 0 & 0 & 6 & 0 & 1 & 0 \\
\hline
\end{tabular}

Table 5 represents the mode of the different categories for both the group leaders and the individual learners. Neither the individual attempts nor the group attempts were left blank. No learner that completed the task individually was able to solve the first problem task. This is in contrast to the seven groups who were all able to solve the first problem before converting to centimetres while two of these groups converted it successfully. Six out of the seven groups were able to give a mathematically sound explanation for the first question whereas this was not true for individual learners. Most of the individual learners had partially correct answers. By this it is meant that learners had begun answering the question in a mathematically sound manner but had either not completed the task or alternatively had then proceeded with an incorrect procedure. Most learners categorised as " $\mathrm{D}$ " had an answer such as learner I4 "we said that the thickness of the paper is 0,1 millimetres thick, we timed that by 10 papers which was equal to 0,1.”. Here the misconception was that as the paper was folded ten times, the thickness would be equivalent to ten layers of paper. Learners obtaining such an answer did not consider the number of layers increased in each time the paper was divided in half. Most groups had a similar answer to that of learner G3:

we changed $0,01 \mathrm{~mm}$ into $\mathrm{cm}$ so it was 0,001 . So each time you fold the paper you times by two because it's two halves. So we times 0,001 by 2 and it becomes 0,002 . So if you take the 0,002 and fold it again and you take the answer from the previous answer and times it by two, and then the answer of that you timed it by two until you get to the end. Which the answer is $1,0243 \mathrm{~cm}$.

The learner converted to centimetres successfully. A correct understanding of the question was shown by the group as they realised that each time the paper was folded, double the previous answer was obtained. Learners used different methods to solve the problem. G6 said a member of his group had actually done the problem in real life. Diagrams and drawing were used by some learners as confirmed by G2 "yes using diagrams actually helps. I never thought so before".

Group 2 and I2's calculation of problem task 1 is shown below. As can be seen Group 2's calculation has been done in logical steps whereas I2's calculation is not as clear. There is no connection made between his first and second line. Figures 1 and 2 show the calculations of group 2 and individual learner two.

\begin{tabular}{|c|c|c|}
\hline 0.02 & $\times 2 \mathrm{~mm}$ & \\
\hline 0.04 & $\times 2 \mathrm{~mm}$ & The height of the pilt in $\mathrm{mm}$ is: \\
\hline 0.08 & $\times 2 \mathrm{~mm}$ & $=10.24 \mathrm{~cm} \mathrm{~mm}$ \\
\hline 0.16. & $\times 2 \mathrm{~mm}$ & \\
\hline 0.32 & $\times 2 \mathrm{~mm}$ & $=10.24 \mathrm{~cm} . \mathrm{mm}$. \\
\hline 0.64 & $\times 2 \mathrm{~mm}$ & \\
\hline 1.28 & $\times 2 \mathrm{~mm}$ & The neight in $\mathrm{cm}$ is: \\
\hline .56 & $\times 2 \mathrm{~mm}$ & $=102.4 \mathrm{mcm}$. \\
\hline
\end{tabular}

Figure 1: Group 2's calculation of problem 1 


Took the $\theta$ measurement of the cardkoard
ond times it bn 10 to get answer
of 0 , lem.

Figure 2: Individual learner 2's calculation of problem 1

Group 2 multiplied the answer by two each time for ten times. However their conversion to centimetres was incorrect. Their conversion illustrates a belief that centimetres are smaller than millimetres. I2's calculation shows that to achieve the answer he multiplied by 10 , corresponding to the second line of his calculation. However this does not explain his first line. He initially believed that as the paper was being divided by two so to must the answer.

$$
10.2 \Delta c m= \pm 0.01 m \cdot m \times 2^{10}
$$

Figure 3: Group 1's final answer in problem 1

Group 1 went a step further in their solution and were able to grasp a connection to exponents. They achieved an answer of $0,01 \mathrm{~mm} \times 2^{10}$. The group was able to conclude that instead of multiplying ten times by two, one could simply multiply by $2^{10}$. What was also of significance was the fact that this group had three black members who communicated in isiZulu (from observation notes of researcher). So, it seemed that the success of the collaborative work could be due to learners communicating in a common language to create meaning to ideas leading to the solution of the problem.

\section{Results from problem 2}

The following question was given as problem task two:

Four men were shipwrecked on an island. Having no food, they went to work gathering pineapples. After gathering the pineapples, they were tired and all fell asleep. After some time, one of the men woke up and was very hungry so he ate $\frac{1}{3}$ of the pineapples - more than his proper share. He then went back to sleep. The second man awoke and being hungry, ate $\frac{1}{3}$ of the remaining pineapples and went back to sleep. The third man did the same. When the fourth man awoke, he took only his rightful share of the remaining pineapples. Then there were 6 pineapples left. How many pineapples did the men gather?

A similar system that was used in question one was adopted to categorise the data in question two. The categories were: (A) mathematically sound calculation with an accurate answer, (B) partly correct solution with calculation shown, (C) no understanding of the question, (D) incorrect answer with no solution, and (E) no answer.

Category "A" was selected if both the answer and the calculation were mathematically correct. For category "B", learners did not achieve the correct answer but showed partial understanding in their solution. Where no proper understanding of the question was shown, category "C" was selected. Category “D” was selected only if an incorrect answer was shown. If no answer was present, it fell into category "E”.

Table 6 illustrates the learners' results both individually and in groups for problem 2 .

Table 6: Categorising learners' results for problem 2

\begin{tabular}{|l|c|c|c|c|c|}
\hline & A & B & C & D & E \\
\hline Group & 0 & 6 & 1 & 0 & 0 \\
\hline Individual & 0 & 2 & 2 & 1 & 2 \\
\hline
\end{tabular}

Neither individual learners nor groups were able to give the correct answer for question two. Two individual learners did not attempt to write an answer and a further individual learner gave only an incorrect answer. All seven groups gave an explanation for their answers, whereas only four individual learners did the same. Most groups had a similar calculation as Group 4, 


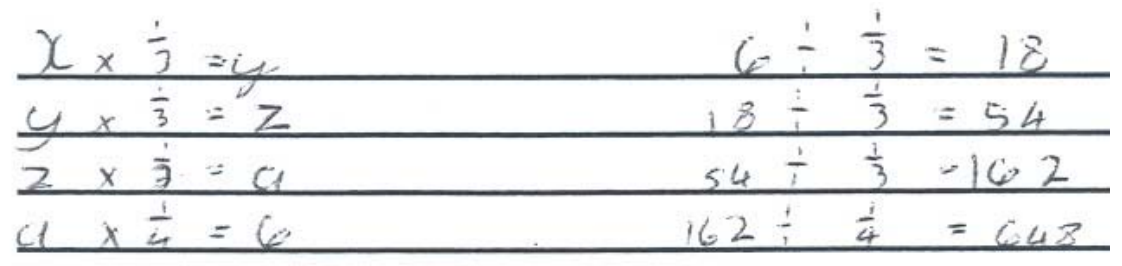

Figure 4: Group 4's results for problem 2

G4 explains his groups answer:

they told us that there were 6 pineapples left and so how many did the man gather? So I started with the 6 and I divided it by 3 because the first guy ate, I mean I divided it by a third because the first guy ate a third and the answer for that was 18. And the second guy ate a third of that. So I divided that by one third which gave me 54 and the other guy, the third guy which gave me 54 . And then the other guy, the third guy, he also ate a third so I divide that by a third, which gave me 54. And then the fourth guy he got a quarter. So after the third guy I got 162 and then the last guy, I get 162 divide by a quarter. So the men gathered 648 pineapples.

The group identified that three of the four men ate $1 / 3$ of what was left and the final man ate $1 / 4$. They failed to comprehend that in order to get the answer, you had to work backwards from 6 and not start at the beginning. I6 realised this as he explains:

Well I didn't finish my one because I didn't have time. But what I did, I said a third times 6 because there was six remaining right. And then the last guy, I mean not the last guy but the third guy ate a third. That's correct and then I timed that and I got 8 and then I did it again with the same answer and then I timed it by a third since the second guy also ate a third. And then I stopped there.

As can be seen, I6 worked backwards from the third "guy" to the "second guy". I6 did not include the pineapples the last man ate in his calculation and failed to mention that the he ate $\frac{1}{4}$ of what was left. No learner acknowledged that the six pineapples was equal to three quarters and that one needed to find out that one quarter was equal to two pineapples.
Even though the group answers were incorrect, they were better reasoned over the individual learners' answers. The group's answers had detailed explanations. This shows that learners had at least attempted to answer the question in their groups. The groups also spent much longer on the two questions as opposed to the individual learners. Individual learners were inclined to read though the question, attempt one answer and leave the question as they thought it was too difficult. Two individual learners received help from each other even though they were instructed not to. As was observed the groups approach to the question was different. At least one member from each group had an initial answer for question two. However, as each learner attempted to explain their answer to the group they would realise that their answer was wrong and would try solve the problem once again. This was particularly evident in group 1 where learners kept arguing with each other.

\section{Participation in groups}

Initially the learners who worked in groups were extremely teacher dependant. They repeatedly asked the teacher for help. This occurred more frequently with second language English speaking learners. When learners were placed in groups, they became less dependent on the instructor and they communicated in the language they were comfortable with. In many instances, the researcher observed that members in a multilingual group switched between languages when communicating with different members within the group. However not all learners worked effectively in the group environment. Some learners complained of others who, even though present, did not take part in the group discussion. As $\mathrm{G} 2$ recalls:

I remember one person in my group and I don't remember them giving any ideas. It's just sometimes when you are working they think, okay I don't understand and I'm just going to sit down and get the answers. 
This same sentiment was echoed by other learners who were unhappy working in groups. It was observed that mainly the low attaining learners did not participate in group discussions. When asked why, they responded that they either could not contribute to the discussion as they did not know what was going on, or they said that the other members in the group were not including them in the discussion and as a result they could not follow the debate. This would agree with learner G2 who suggested that if learners do not understand the work they do not participate in it. After the researcher explained to learners that to complete the task all members must participate, the low attaining learners still seemed to hold back and listen, rather than engaging in the discussion. However towards the end of the lesson, it was observed that in some circumstances the low attaining learners did contribute to their group's discussion and were able to explain their group's answers. Learning is evident as in one particular case; a learner was troubled as he was not able to grasp the question. The learner's group proceeded to explain the question to him. Once he understood it, he was able to contribute to the discussion and became one of the main candidates that solved the problem.

Researcher: I told you that you had to try solve [the question] first on your own. How did you find, or feel trying to solve it on your own first?

G2: I just thought that this was too hard for me

Researcher: Really?

G2: $\quad$ Yes mam.

Researcher: And when you got into a group?

G3: I saw that it was getting easier and I saw that I understood. And I realised that the only reason I thought it was hard was because I didn't understand.

G2 realised that not understanding what the question asked hindered his problem solving skills. I6, who completed the task individually, initially expressed he preferred working on his own but later he to changed his mind and felt that working in pairs would have been more beneficial. I3 repeatedly uttered throughout the interview that he "would have loved to be in a group". The problem he felt with working individually was that he “couldn't ask anyone for help”. I3 had partially answered the first question and had not attempted to answer the second one.

\section{Composition of groups}

Dissatisfaction was raised concerning group members who did not participate in their group discussion. A learner from group 4 was in a different class to those in his group and hence did not know any group members. He was not friendly towards the members in his group even though they tried to include him and he did not participate in the group discussion. G4 commented that "he totally ignored [the group] and did the whole thing by himself." G4 also acknowledged that he received help from members of other groups, as his group had not functioned at all. In the interviews it was confirmed that learners found it difficult working in groups with people they did not know, as G2.2 comments "you might not even know that person but it will be hard just to come and talk to them and be friends with them" and as G2 commented "if I start talking to a stranger its all awkward and tense". This suggested that learners feel more comfortable in groups where they are familiar with each other. Learners may not have the confidence working with the members of the group that they had been placed in, and would have preferred being in different groups.

The above two examples does not reflect badly on collaborative learning as a whole. Learners in groups 1, 2, 5, 6 worked extremely well together. G2 felt that everyone participated and were helpful. He also believed that he "wouldn't have found [the answer] on [his] own." Group 1 had two strong willed members who tried to convince each other and the rest of the group that their answer was correct. This is an indication that collaborative learning had taken place as learners were discussing various options and were debating their validity. All groups members were involved in the whole lesson even though individual members may not have been involved in the group discussion.

Despite learners dissatisfaction about working in groups, they expressed they do work in informal groups in class. Two learners felt that they did not normally work in groups unless they were unable to understand or complete a problem. At this stage they felt that asking another learner would result in a better understanding and may result in the problem being solved. Collaborative learning did take place in the lesson even though it was not necessarily in the assigned groups. Learners still engaged with each other to find the solution to the problem. 
Learners expressed that one of the major problems in the lesson was the dynamics of the group. Most learners believe they achieve a greater knowledge in a group environment as opposed to working individually, but thought that if they were not placed in a good group they would rather work alone. Learners felt that friendship groups would not be the best idea as they would not get any work done. All learners felt that if they were placed in different groups the outcome of the lesson may have been different. Learners felt that making the groups equal with behavioural problems and academics would result in better results.

\section{Discussion of data}

\section{Collaborative learning versus individual problem solving skills}

Learners that were placed in groups were found to have a greater ability to solve problems than those that completed the worksheet individually. This would agree with Barkley, Cross and Major (2005), and Lyle (1996) who found that learners who worked collaboratively had a greater problem solving ability. Learners working in informal groups felt that it was helpful. Even learners who believed that they did not work in groups acknowledged that they only asked for help when they were not able to achieve the answer on their own. This shows that learners believe that working collaboratively is more successful than working individually when they encounter a difficult problem.

The language of the worksheet was too difficult for learners as they did not initially grasp what the question was asking and hence were not able to solve the problem. The structure of the task is crucial to reduce uncertainty and ensure learners understand what is expected of them (Lyle, 1996). Learners had not been given questions in a similar fashion to this, but had solved problems of a similar nature from their text books. A worksheet however is seen as an important document and not as just another exercise. Learners should be given similar worksheets to obtain more experience of what is expected of them.

\section{Collaborative learning versus individual engagement}

The data shows that learners working in groups are more relaxed and are able to share valuable information with each other to arrive at the answer which has an advantage over learners who work individually. This does depend on the dynamics of the group. Individual learners were more demanding on the teacher whereas learners working in groups were not as demanding. This would agree with Barkley et al. (2005) who argues that collaborative learning encourages learner centred teaching. Barkley et al further stresses that working in a group can improve the learner holistically. The placement of learners in groups allowed for academically strong learners to help low attaining ones. Both academically strong learners and low attaining ones were advantaged by collaborative learning, as the low attaining learners were able to grasp the meaning of the question, enabling them to contribute towards the group discussion. The academically stronger learners' would have gained conceptual understanding while explaining the question to low attaining learners, as indicated by Barkley et al. More research may be done to verify this assumption. Allowing learners to choose their groups may have curbed learners' anxiety of working with those they do not know. The results show that learners found it difficult working in the groups they had been placed in especially when learners were not familiar to each other. Previously learners worked more effectively in non official groups that they developed on their own. As Lyle (1996) shows, familiarity with each learner in a group influences how the learners will interact, hence learners who are friends work better together.

\section{Implications and recommendations}

\section{Implications for collaborative learning in multilingual classrooms}

The use of two or more languages, usually English and other indigenous languages, has become a frequent observation in multilingual classes in South Africa (Vorster, 2008). Code-switching needs to be promoted on a larger scale in an informal or structured manner. The study has shown that collaborative learning (allowing learners to switch between languages) has a significantly greater success rate than individual engagement, although it is advised that further research be conducted to clarify this point. The role of language for conceptualisation and for mathematical problem solving skills has long been acknowledged in other researches (Genter \& Goldin-Meadow, 2003; Pimm, 1987, 1991; Usiskin, 1996; Vygotsky, 1962). This would indicate that mathematical teachers must make use of collaborative learning in the classroom not only specifically for fractions and decimals but for all aspects of mathematics. Collaborative learning promotes the interaction between low attaining 
learners and academically stronger learners, which enables the stronger learners to help the low attaining ones improve their understanding. This invariably gives the teacher more free time to ensure that learning is taking place by ensuring learners are on task and assisting where necessary. Collaborative learning also allowed the lesson to be more learner centred in line with the RNCS (Department of Education, 2002). Caution once again must be taken in the placement of learners in groups. A suggested method may include placing learners in the same group for a long period of time to allow learners to gain confidence in their group members.

\section{Implications for further research}

Further research should be conducted to verify the findings of this study. Other possible research would be:

- to determine if group dynamics improve problem solving skills

- to determine if placement in a group for extended periods of time improves the group dynamics

- learners' difficulties in fractions and decimals

- to determine if collaborative learning in multilingual classes improves both the low attaining learner and the academically strong learners simultaneously

\section{References}

Arora, A. (2003). Examining the problem-solving achievement of Grade 8 students in TIMMS 2003. TIMSS \& PIRLS International Study Centre, Boston College, USA.

Barkley, E. F., Cross, K.P., \& Major, C. H. (2005). Collaborative learning techniques: A handbook for college faculty (1st ed.) San Francisco: JosseyBass.

Barns, H. (2005). The theory of Realistic Mathematics Education as a theoretical framework for teaching low attainders in mathematics. Pythagoras, 6, 42-57.

Barwell, R. (2005). A framework for the comparison of PME research into multilingual mathematics education in different sociolinguistic settings. In H. L Chick,. \& J. Vincent (Eds.), Proceedings of the $29^{\text {th }}$ Conference of the International Group for the Psychology of Mathematics Education, 2 (pp. 145-152). Melbourne: University of Melbourne.
Buffer, A. \& Leigh, G. (2005). Facilitating positive epistemological change through the development of multi-representational problem solving skills in physics. In R. Pinto \& D. Couso (Eds.), Proceedings of the 5th International Conference of the European Science Education Research Association (pp. 361- 363). Barcelona.

Cooper, B. \& Bunne, M. (2004) Constructing the 'legitimate' goal of a 'realistic' maths item: A comparison of 10-11 and 13-14-year-olds. Mathematics Education, (pp. 69-90). London: Routledge Falmer.

Department of Education. (2002). Revised National Curriculum Statement Grades R-9 (Schools): Mathematics. Pretoria: Department of Education.

Dlamini, C. (2008). Policies for enhancing success or failure? A glimpse into the language policy dilemma of one bilingual African state. Pythagoras, 67, 5- 13.

Gentner, D., \& Goldin-Meadow, S. (Eds.) (2003). Language in mind. Advances in the study of language and thought. Cambridge: MIT Press.

Kilpatrick, J., Swafford, J., \& Findell, B. (2001). Adding it up: helping children learn mathematics. Washington, DC: National Academy Press.

Lyle, S. (1996). An analysis of collaborative group work in the primary school and the factors relevant to its success. Language and Education, 10 (1), 13-31.

Pimm, A. (1987). Speaking mathematically, communicating in mathematics classrooms. London: Routledge.

Pimm, D. (1991). Communicating mathematically. In K. Durkin \& B.Shire (Eds.), Language in mathematical education: Research and practice (pp 18 - 24). Philadelphia: Open University Press.

Reddy, V. (2006). Mathematics and Science achievement at South African Schools in TIMSS 2003. Cape Town: Human Science Research Council Press.

Setati, M., \& Barwell, R. (2008). Making mathematics accessible for multilingual learners. Pythagoras, 67, 1 - 4 .

Usiskin, Z. (1996). Mathematics as language. In P. C. Elliot, \& M. J. Kenney (Eds.), Communication in mathematics: K-12 and beyond. 1996 Yearbook (pp 231 - 243). Reston: NCTM.

Vorster, H. (2008). Investigating a scaffold to codeswitching as strategy in multilingual classrooms. Pythagoras, 67, 33 - 41.

Vygotsky, L. S. (1962). Thought and language. New York: MIT Press. 